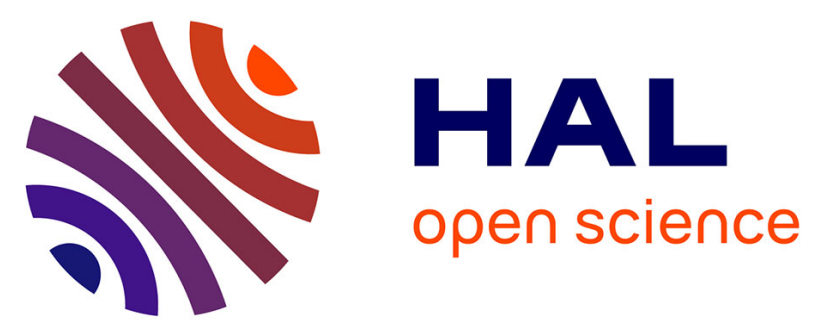

\title{
Damage law identification from full field displacement measurement: Application to four-point bending test for plasterboard
}

\author{
Amine Bouterf, Stéphane Roux, François Hild, Guillaume Vivier, Xavier \\ Brajer, Eric Maire, Sylvain Meille
}

\section{To cite this version:}

Amine Bouterf, Stéphane Roux, François Hild, Guillaume Vivier, Xavier Brajer, et al.. Damage law identification from full field displacement measurement: Application to four-point bending test for plasterboard. European Journal of Mechanics - A/Solids, 2015, 49, pp.60-66. 10.1016/j.euromechsol.2014.06.001 . hal-01068546

\section{HAL Id: hal-01068546 https://hal.science/hal-01068546}

Submitted on 25 Sep 2014

HAL is a multi-disciplinary open access archive for the deposit and dissemination of scientific research documents, whether they are published or not. The documents may come from teaching and research institutions in France or abroad, or from public or private research centers.
L'archive ouverte pluridisciplinaire HAL, est destinée au dépôt et à la diffusion de documents scientifiques de niveau recherche, publiés ou non, émanant des établissements d'enseignement et de recherche français ou étrangers, des laboratoires publics ou privés. 


\title{
Damage law identification from full field displacement measurement: Application to four-point bending test for plasterboard
}

\author{
Amine Bouterf ${ }^{1,2}$, Stéphane Roux ${ }^{1}$, François Hild ${ }^{1}$, Guillaume Vivier $^{2}$, \\ Xavier Brajer ${ }^{2}$, Eric Maire ${ }^{3}$, Sylvain Meille ${ }^{3}$ \\ 1: Laboratoire de Mécanique et Technologie (LMT-Cachan), Ecole Normale Supérieure \\ de Cachan / CNRS-UMR8535 / PRES UniverSud Paris \\ 61 avenue du Président Wilson, F-94235 Cachan Cedex, France \\ 2: Saint-Gobain Recherche, \\ 39 quai Lucien Lefranc, B. P. 135, F-93303 Aubervilliers Cedex, France \\ 3: MATEIS, CNRS-UMR5510 / INSA-Lyon, \\ 7 Avenue Jean Capelle, F-69621 Villeurbanne Cedex, France
}

\begin{abstract}
Plasterboards are tested in four-point bending up to failure, and digital image correlation is used to follow the kinematics and the progressive degradation of the structure all along the test. Although numerous distinct core cracks are clearly observed, it is proposed to identify the behavior of plasterboard through a homogenized continuum description where the progressive degradation of the bending stiffness is described through a damage law. A specific procedure for the identification is presented where experimental imperfections and symmetry breakdown are accepted and accounted for. The identification procedure is shown to provide constitutive parameters with a remarkably small variability.
\end{abstract}

Keywords: Damage identification, Digital Image Correlation (DIC), Love-Kirchhoff kinematics.

\section{Introduction}

The use of plaster as a building material has a very long and rich history. In their quest for producing a robust, light-weight, insulating structure element for the building industry, the concept of plasterboard was invented 
as early as in 1894 by two engineers from New York, A. Sackett and F.L. Kane. Plasterboard is nowadays the most commonly used low-cost building plates within the construction industry. This success is mostly due to the fact that plasterboards can be used in many applications, and engineered with enhanced performance for acoustic and fire requirements (Vimmrová et al., 2011). Gypsum board producers are still working for improved properties, or similar properties but with lower densities. Weight has direct commercial consequences, as any density saving impacts directly on production, transport, environmental and economical costs. Moreover, lightweight boards facilitate handling and make installation easier and more secure.

Two main methods are commonly used for the production of porous gypsum. In the first method, gas bubbles are formed in the gypsum paste through chemical additives. The second one consists of foaming by air entrainment in the wet gypsum paste (Vimmrová et al., 2011; Çolak, 2000). The relationship between microstructure and mechanical properties of raw plaster or core of the board (Murat et al., 1974; Coquard, 1992; Meille, 2001), or the evaluation of fire resistance of a partition wall with plasterboards has been thoroughly studied (Sakji, 2006; Sakji et al., 2008). However, plasterboard as such has received only little recognition as a structural part; its mechanical behavior and fracture resistance are scarcely investigated in the literature, although from manufacturing to installation, mechanical properties such as the flexural strength of the boards are crucial. Benouis (1995) showed the orthotropic nature of the plasterboard which is a consequence of tensile behavior of the paper. Some studies on the mechanical properties of syntactic foam core sandwich composites are also available. In these studies it is observed that the skin (paper) contributes to an increase of up to $40 \%$ in estimated flexural strength, depending on starch content in adhesive between core and skin (Gupta and Woldesenbet, 2005). Other studies on mechanical properties of gypsum sheathing found that the bending strength of gypsum sheathing depends on the strength of the adhesive bond between the facings and the gypsum core (McGowan, 2007).

Therefore, it is critical for the producers to strive to create a board of even lighter weight that still passes the standard tests. To achieve this goal, it is important to make progress on the characterization of the failure mechanism in bending tests and to identify the different stages of damage and failure. Progress along these lines opens new pathways for optimized light wallboards, and hence efficient light frame construction.

In the present paper, Digital Image Correlation (DIC) is used to measure 
the kinematics of the plasterboards during four point bending tests up to failure. From this measurement, the ambition is to provide an effective constitutive law within the framework of plate theory (i.e., without distinguishing core and facings) to be used for describing wallboard within arbitrary flexural loadings up to ultimate failure.

Since the pioneering works of Sutton et al. (1983); Chu et al. (1985), DIC has been widely used not only in the academic world but also in industry. Recent advances enable the sought displacement field to be decomposed onto a suited library (Hild and Roux, 2006) such as finite element shape functions (Besnard et al., 2006). This type of technique has been used based on beam/plate kinematics (Hild et al., 2009; Réthoré et al., 2009; Leplay et al., 2010). The main interest of this approach is that it provides full kinematic fields expressed in standard form for beam/plate theories. Moreover, because of the reduced number of degrees of freedom, measurement uncertainties are significantly reduced. Because the kinematic description has a direct mechanical meaning the interface with a further modeling for identification purposes is direct and does not involve any projection error. However, it may be noted that if the displacement field significantly deviates from that of elastic plate theory (say because of pronounced damage or cracking), then an integrated approach may reveal inaccurate. For this reason, the motion has been analyzed without specific assumption, and then the two-dimensional kinematic field has been reduced to 1D plate kinematics.

Examples of identification of elastic (or more complex constitutive laws) based on DIC measurement are numerous (Forquin et al., 2004; Hild and Roux, 2006; Périé et al., 2009; Eberl et al., 2010; Leplay et al., 2010; Grédiac and Hild, 2012). However, damage models have been less studied. Chalal et al. (2004) resorted to the virtual fields method to determine the parameters of a linear relationship between the damage parameter and the local shear strain. An alternative route is given by the equilibrium gap method that aims at identifying fields of elastic contrasts (Claire et al., 2002, 2004), which may be reinterpreted a posteriori as damage fields (Claire et al., 2007; Crouzeix et al., 2009). More recently, it has been shown that the same type of formalism can be used to directly identify the parameters of the damage law in the case of isotropic (Roux and Hild, 2008) and anisotropic (Périé et al., 2009; Ben Azzouna et al., 2011) descriptions of damage.

Dedicated examples suited to beam-like geometries are less common (Forquin et al., 2004; Leplay et al., 2010; Hild et al., 2011). In particular, Leplay et al. (2010) used the central section of a four point bending test to 
evaluate a damage law of a ceramic material. In that case, the kinematics (i.e., uniform curvature) decouples from the constitutive law, and hence identification is direct. This procedure was shown to be accurate, but it does not tolerate any deviation from the basic hypothesis of constant curvature. Further, to account for local buckling in steel beams (Hild et al., 2011), damage variables have been introduced either in the buckled zone or lumped in a hinge as described in the framework of Lumped Damage Mechanics (Cipollina et al., 1995).

A comparable goal is aimed at in the present study, but with arbitrary test geometry of the plate, namely four-point but also three-point bending, or any arbitrary departure from a perfect test. The inhomogeneous kinematics makes the problem more involved as it calls for a dedicated procedure. Let us stress that the information that can be extracted from DIC is too detailed and spatially resolved for the ultimate goal as the details of core crack inception, their shape size, density, or opening are easily accessed but would drive naturally to a probabilistic approach describing crack initiation in the core, and interface debonding. Although it may appear as paradoxical, the too fine description of the kinematics is challenging for the identification of a homogeneous constitutive law (Gras et al., 2013).

In the following, the methodology is illustrated by analyzing a bending test on plasterboard plate. In Section 2, the experimental conditions are described, and first analyses of kinematic data extracted from displacement measurements thanks to DIC are presented. The identification procedure is summarized in Section 3. First, the identification of the elastic modulus of the plasterboard is proposed. Then, the identification of a damage law is detailed and applied to the experiments on plasterboard plate.

\section{Experimental procedure}

\subsection{Plasterboard}

Plasterboard is a material composed of lightweight gypsum core lined with paper coatings. Adhesion between paper and gypsum core is promoted by the addition of starch. The latter has definite advantages over other binders in applications for building interior sandwich panels because it is readily available, environmentally friendly, inexpensive, and renewable. 


\subsection{Material and sample geometries}

Specimens used in the experiment are prepared from industrial plasterboard plates. The tested samples are cut out at a size $160 \times 50 \times 13 \mathrm{~mm}^{3}$. They are tested on a four-point bending rig with the following characteristics:

- outer support span, $D_{\text {lower }}=150 \mathrm{~mm}$;

- inner yoke span, $D_{\text {upper }}=40 \mathrm{~mm}$;

- prescribed displacement speed $5 \times 10^{-2} \mathrm{~mm} / \mathrm{min}$ until failure;

Load-deflection curves are monitored all along the test.

\subsection{Full field measurements}

Global DIC is used to measure the displacements of the lateral surface with Correli-Q4 (Besnard et al., 2006). We refer the reader to the latter publication for further details on the specific finite-element DIC code used herein. Let us however stress that although the displacement field is decomposed over finite element shape functions, there is no mechanical modeling involved at this stage. The reference and the last deformed image before failure are shown in Figure 1. A random speckle pattern has been applied on the sample surface to enhance the image contrast. Digital images are recorded during the deformation process using a digital single lens reflex camera (Canon 40D). The image definition is $3888 \times 2592$ pixels and stored with 8-bit digitization. The displacement at image $n$ is assessed by correlating the $n$-th image with the initial image (unloaded state considered as the reference). The acquisition frequency is one image per five seconds. The physical size of one pixel is $37 \mu \mathrm{m}$. The size of the Q4 elements has been chosen to be 12 pixels or about $450 \mu \mathrm{m}$. A priori estimates of the displacement resolution are 0.04 pixel or $1.5 \mu \mathrm{m}$.

After the DIC evaluation of the displacement, the measurement data are projected onto plate theory kinematics by computing the deflection and rotation along any cross section. The ROI is chosen such that its horizontal axis coincides with the neutral axis of the sample. The vertical displacement field is then averaged in each section to determine the displacement field for the neutral axis. The latter is then compared with the displacement field calculated numerically via the plate model developed hereafter. The curvature fields are calculated by centered finite differences of the slope field, itself the result of the derivation of the measured displacement field.

Note that the Love-Kirchhoff kinematics (reducing to Euler-Bernoulli kinematics in the present case) could have been imposed directly in the DIC 
analysis (Hild et al., 2009). A gain in uncertainty is expected from such a procedure when it can be assumed that the elastic properties of the sample remain constant along the plate axis for extended intervals (Hild et al., 2011). For damage, this would imply that a large density of small microcracks is present. As will be seen in the sequel, this assumption is not fulfilled, and therefore it was chosen not to resort to such a potentially limiting assumption and the projection procedure was chosen in this study.

\subsection{Experimental results}

A typical load-deflection curve for plasterboard plate is presented in Figure 2. It exhibits two parts separated by a kink; the linear part corresponds to the elastic regime, while the second nonlinear part is the manifestation of the damage regime. Experimentally obtained load-deflection curves obtained for ten different samples under the same four point bending test fixture are shown in Figure 3. Some of the general observations from these curves of the samples during tests are listed below:

1. within the elastic region of the load-displacement curves, where no significant damage is induced, the responses of the specimens to the applied loads are similar. This is due to a comparable stiffness. However, an initial nonlinearity resulting from initial imperfect contact shows a much stronger variability;

2. the load that corresponds to the inception of the first crack in the plaster core shows a rather narrow scatter;

3. because of the flat shape of the load displacement response, the peak load is rather well defined as $271 \pm 19 \mathrm{~N}$, but the deflection at peak load exhibits a much broader scatter $3.0 \pm 0.67 \mathrm{~mm}$.

Figure 4 shows maps of the longitudinal (i.e., horizontal) displacement $u_{D I C}(x, y)$ and longitudinal strain $\epsilon_{x x}(x, y)$ on the observed specimen side as obtained from DIC at the three points $A, B, C$ indicated in Figure 2. At point $A$, (Figure 4(a)), the elastic regime still prevails; the displacement field is as expected from plate theory, and no discernible crack is observed in the strain field. At the kink of the load displacement curve, point $B$ (Figure 4(b)), the inception of the first macroscopic crack occurs in the plaster core near the tensile face of the specimen. The strain map shows a very pronounced maximum on top of the crack as the discontinuity contributes to the (apparent) strain. Such observations allow for an easy determination of the presence and position of a crack in the specimen. The crack does not 
propagate through the thickness, nor does it lead to the sudden failure of the specimen for the paper facing is able to bear the load transfer from the plaster core. This is a manifestation of the "ductility" and enhanced strength provided by the paper facing. At point $C$, (Figure 4(c)) the specimen just before failure shows multiple transverse cracks. Final failure of the sample occurs when the paper bridging one of the cracks cannot withstand the tensile load it is subjected to. The crack opens up and propagates to the opposite face. Such results have already been reported in the literature (Benouis, 1995).

A description based on the presence of multiple cracks can be easily designed for such specimen following similar developments proposed for ceramic matrix composites. The inception of transverse matrix cracks does not directly lead to failure, but rather allows for a progressive degradation of the fibre/matrix interface giving rise to an apparent ductility that can be described at different scales (Aveston et al., 1971; Evans et al., 1994; Hild et al., 1996). The matrix crack density tends to be almost periodic for a high value of the matrix Weibull modulus, and crack separation corresponds to a shielding mechanism (described by, say, a shear lag model) and analytical models have been very successful at describing either probabilistically the formation of successive cracks (Curtin, 1991; Hui et al., 1995), or deterministically as a homogenized damage (Hild et al., 1994; Hild and Feillard, 1997). The second route is followed herein, but rather than reconstructing the constitutive law from individual constituent behavior, the effective behavior of the board as a whole is sought.

\section{Identification scheme}

The identification process consists of exploiting the measured dsiplacement fields obtained from DIC. First, the identification of the elastic modulus of the plasterboard is proposed. Then, the identification of a damage law is detailed.

\subsection{Modeling}

We resort to a Love-Kirchhoff description and hence its applicability relies on the satisfaction of the following assumptions:

- straight lines normal to the mid-plane remain straight and normal to the mid-plane,

- the plate deflection due to shear stresses is neglected, 
- the slope of the plate is assumed to be negligible compared to unity. In addition, invariance in the $z$-direction is assumed (cylindrical flexion).

Considering a simply supported plate subjected to lateral in-plane loading, the bending moment $M(x)$ is determined by solving the equilibrium equation (1), where the applied transverse loads are denoted as $q(x)$

$$
\frac{\mathrm{d}^{2} M(x)}{\mathrm{d} x^{2}}=q(x), \quad 0 \leq x \leq L
$$

For the four point bending test, these forces at the four points of contact are denoted $q_{i}$ at positions $x_{i}$ for $1 \leq i \leq 4$, as shown in Figure 5). In the elastic regime, the local bending stiffness, $\kappa(x)$ is constant and equal to $\kappa_{0}$

$$
\kappa_{0}=\frac{E I}{\left(1-\nu^{2}\right)}
$$

as a function of Young's modulus $E$, Poisson's ratio $\nu$, and inertia of the cross section, $I=b h^{3} / 12$ with $b$ the specimen width, and $h$ its thickness. The deflection $v(x)$ obeys

$$
\kappa(x) \frac{\mathrm{d}^{2} v(x)}{\mathrm{d} x^{2}}=M(x), \quad 0 \leq x \leq L
$$

where $L$ is the outer fixture support span (the sample is supported at $x_{1}=0$ and $\left.x_{4}=L\right)$. The direct problem consists of solving the differential equation for $v(x)$ using as input the applied load $q(x)$, the stiffness distribution $\kappa(x)$, and the boundary conditions $v(0)=0, M(0)=0, v(L)=0$ and $M(L)=0$.

In the four-point bending test, it is usually assumed that two equal forces are applied symmetrically with respect to the specimen center (Figure 5), which leads to a constant plate curvature, strain, and stress in the central part of the specimen $x_{2} \leq x \leq x_{3}$. However in practice, the load is applied through cylinders in contact with the plaster board to limit indentation effects, and hence it is difficult to ascertain the exact location of the equivalent point load. Moreover, a slight dissymmetry is commonly observed, so that the ideal four-point bending description is only a crude approximation of actual tests. Further, damage will very severely amplify those imperfections.

\subsection{Elastic identification}

For the case of statically determinate simply supported plates and uniform bending stiffness, it is simple to solve for the deflection through quadratures. 
To take into account the real conditions of the test, the model based on plate theory has been considered without postulating a priori symmetry, and exact positions of the load application points. Although the individual loads $q_{2}$ and $q_{3}$ are not assumed to be known individually, the total load $F=q_{2}+q_{3}$ is measured. This can be taken into account by introducing individual loads and positions as unknowns, subjected to known constraints.

The identification is performed through the minimization of the quadratic differences between the measured and modeled deflection of the plate. The objective function to be minimized is written as

$$
\begin{aligned}
\mathcal{T}\left(x_{i}, q_{i}, \kappa_{0}, U, \Omega\right)= & \left.\int_{0}^{L}\left(v_{D I C}(x)-v_{\text {mod }}\left(x, x_{i}, q_{i}, \kappa_{0}\right)\right)-U-\Omega x\right)^{2} \mathrm{~d} x \\
& +\lambda\left(q_{2}+q_{3}-F\right)
\end{aligned}
$$

where $x_{i}$ is the location of the applied load $q_{i}, U$ is a translation, and $\Omega$ a rotation as a rigid body motions inevitably occur in the experiment. The total load, $F$, which is measured in the experiment is accounted for as an additional constraint, $q_{2}+q_{3}=F$, through a Lagrange multiplier, $\lambda$. Note that $q_{1}$ and $q_{4}$ are naturally determined by the balance equations. $\mathcal{T}$ is minimized by a progressive adjustment of its parameters through a NewtonRaphson scheme. This allows for an excellent match between the actual test including its imperfection and the modeling.

In Figure 6, the identified positions of the applied load point and their theoretical positions (broken line) are plotted for ten different tests in the elastic regime. The identification procedure leads to average positions $x_{2}=$ $55.5 \pm 2.7 \mathrm{~mm}$ and $x_{3}=94.3 \pm 3.2 \mathrm{~mm}$. The average values are quite close to the nominal values $x_{2}^{\text {nom }}=55 \mathrm{~mm}$ and $x_{3}^{\text {nom }}=95 \mathrm{~mm}$. However, the fluctuations around these values are estimated to be significant. In the test, the load is applied through contacting cylinders of radius $25 \mathrm{~mm}$, and hence a small rotation, or indentation of the paper facing may result in a large shift in the effective load application point.

The effective elastic modulus of the specimen (computed from the bending stiffness as if the plate were made of a homogeneous material, i.e., ignoring the partition between plaster core and facings) is another output of the identification procedure. The elastic identification procedure has led to a Young's modulus of $2.52 \pm 0.18 \mathrm{GPa}$. Let us underline that in spite of the observed scatter in the geometrical parameters, the standard deviation of the elastic property is quite small (i.e., $7 \%$ ). It is of interest to compare these estimates 
with those obtained from the classical test equation (assuming nominal values and perfect symmetry). This estimate amounts to $2.40 \pm 0.28 \mathrm{GPa}$. Although both estimates are consistent, it is observed that the latter evaluations have a much broader coefficient of variation (i.e., $12 \%$ ) than that obtained with the proposed procedure. This feature already shows one benefit of having a method that is tolerant to unavoidable imperfections of the test set-up. As will be shown below, this advantage is even more important for (and even key to) the evaluation of damage.

\subsection{Damage identification}

When the applied load exceeds the cracking load of the plaster core, cracks develop and propagate inside the tensile part of the bent plate, thereby reducing the bending stiffness, $\kappa(x)$, of the cross section. In the present approach, it is assumed that degradation of the flexural stiffness $\kappa(x)$ is accounted for by the classical damage parameter, $d(x)$, such that

$$
\kappa(x)=\kappa_{0}(1-d(x))
$$

Interpretation of Equation (5) as a constitutive law means that $d(x)$ is not an arbitrary function of the position $x$, but rather, $d$ is a deterministic function of the maximum curvature $\chi(x)$ experienced in the past by the current cross section, $x$.

Accounting for Equation (5) in Equation (3) yields

$$
\kappa_{0}(1-d(\chi)) \chi(x)=M(x), \quad 0 \leq x \leq L
$$

with

$$
\chi(x)=\frac{\mathrm{d}^{2} v(x)}{\mathrm{d} x^{2}}
$$

The parameter of the constitutive law relating damage to the curvature, $d(\chi)$, is collectively denoted $\alpha$. The chosen algebraic expression is not specified at this stage, and will be discussed below.

The deflection is computed as a solution to this nonlinear differential equation by numerical means. The curvature is calculated through finite differences of the deflection using the mid-point rule. Finally, the minimization of the quadratic differences of experimental and modeled deflections (see Equation (4)) is proposed in the same spirit as for the elastic regime. Because of the stability observed in the previous determination of the geometry of the test, and to limit the number of unknowns, the positions of the applied 
load points have been considered as equal to their nominal values. Thus the minimization is performed over the parameter of damage law, $\alpha$, the applied loads $q_{i}$ (subjected to known total load), and rigid body motions $U$ and $\Omega$.

It is to be stressed that no specific constraints on the expression of $d(\chi)$ are limiting (apart from trivial expectations such as a monotonic increase or $d(\chi=0)=0$. Several algebraic forms have been tested, leading to comparable evaluations of the damage law. A simple expression with threshold is chosen to illustrate the results of the identification. Damage is here postulated to obey the following form

$$
d(\chi)=\max \left(1-\frac{\alpha}{|\chi|}, 0\right)
$$

where $\alpha$ is the constitutive parameter to be identified. From this equation it is apparent that no damage occurs for $|\chi|<\alpha$, and hence $\alpha$ also plays the role of a threshold. Note that only positive curvatures are considered here, and hence even if upside down symmetry is broken (say because of different paper facings) this will not be probed in the present experimental test.

Figure 7 shows the obtained fit of the plate deflection just prior to failure, together with the measured deflection. A very good agreement is obtained. It should be emphasized that the proposed description is a homogeneous damage law, whereas the actual degradation mechanism consists of discrete cracks. Thus a perfect match between measurement and modeling can no longer be expected. However, for practical purposes, the homogeneous damage representation is much more satisfactory than a discrete crack picture that would call for a probabilistic framework. Among the different strategies that would allow for the identification of the "equivalent" damage law, the present one has the advantage to match at best the measured behavior in an inhomogeneous test, including significant damage gradient, either because the test would be a three point bending one, or because of the natural breakdown of symmetry occurring in four point bending. The excellent quality of the fit to the deflection profile up to failure is a further evidence that the homogeneous damage picture does not betray the actual behavior in a very significant fashion.

Figure 8 shows the damage variable as the function of the curvature for one sample for all load levels. Note that each load level is analyzed independently, and a new set of parameter $\alpha$ is measured. However, when all identified $d(\chi)$ laws are plotted on the same graph, a low scatter is observed. It is important to note the existence of a clear threshold curvature $\left(\sim 2 \times 10^{-4}\right.$ 
$\mathrm{mm}^{-1}$ ) for damage initiation. When the curvature exceeds this threshold curvature, a sudden increase of damage is observed followed by a slower one. The onset of damage is easily interpreted as the inception of cracks in the plaster core. A weibull distribution for the plaster strength with a Weibull modulus typically in the range from 5 to 10 would reproduce such a behavior. After crack initiation, the tensile load in plaster is reduced and transferred to the paper facing, and this in a region whose extension is of the order of the plasterboard thickness. Thus the damage mechanism can be compared to the derivation of damage in unidirectional ceramic matrix composites. Crack initiation finally saturates due to screening effects with a well defined distance between cracks (as can be seen in Figure 4(c)). At this stage, the progressive softening of the paper coating due to the increased stress in front of cracks contributes to global damage, yet with a slower rate of increase.

Figure 9 shows the change during a test of the two determined forces applied at positions $x_{2}$ and $x_{3}$ (i.e., including the entire damage regime). It is clearly observed that after the first macroscopic crack occurs in the plaster core, the test becomes dissymmetric and the load is mostly concentrated on $q_{3}$. The proposed identification procedure reveals a much more complex load distribution than what is traditionally assumed for the 4-point bending. This result displays very large differences between the identified load distribution and the expected theoretical value (i.e., half of the measured load). In particular, the specimen central zone is not subjected to a uniform bending moment.

\section{Summary}

Four-point bending tests have performed on plasterboards specimen until failure. DIC allows the mechanisms of mechanical degradation to be investigated, namely, multiple core cracking, paper facing debonding, load redistribution. However, the resulting portray would naturally be a probabilistic framework, involving too sophisticated a modeling for most practical purposes. The choice has been made to select a deterministic damage law to account for the bending strength of plasterboard, and hence a nonlinear identification procedure has been proposed. The methodology based on Digital Image Correlation allowed us to identify simultaneously: - the boundary conditions of the test;

- the bending stiffness; 
- the full damage behavior law.

The results show that the proposed procedure is very effective as it captures the imperfections of the test, and in particular the breakdown of symmetry that inevitably occurs in the damage regime. It is shown that this dissymmetry can be extremely large in the present case, and hence a classical analysis assuming an ideal test would lead to erroneous results. Note that even in the elastic regime, such a procedure allowed for reducing the scatter in the bending rigidity to half its value when a standard identification is carried out.

The methodology proposed in this study can be applied straightforwardly to other quasi-brittle materials or structures such as reinforced concrete or ceramic matrix composites.

\section{Acknowledgements}

This work has been financially supported by Saint-Gobain Recherche and the ANRT through grant no. 2010/567. We wish to thank particularly René Gy for useful and stimulating discussions.

\section{References}

Aveston, J., Cooper, G. A., Kelly, A., 1971. Single and Multiple Fracture. Proceedings National Physical Laboratory: Properties of Fiber Composites, (IPC Science and Technology Press, Surrey (UK)), 15-26.

Ben Azzouna, M., Perie, J.N., Guimard, J.M., Hild, F., Roux, S. 2011. On the identification and validation of an anisotropic damage model by using full-field measurements. International Journal of Damage Mechanics 20(8), 1130-1150.

Benouis, A., 1995. Comportement mécanique des ouvrages en plaques de plâtre sur ossature métallique. PhD thesis, Ecole Nationale des Ponts et Chaussées, France.

Besnard, G., Hild, F., Roux, S., 2006. "Finite-element" displacement fields analysis from digital images: application to Portevin-Le Chatelier bands. Experimental Mechanics 46, 789-803. 
Chalal, H., Meraghni, F., Pierron, F., Grédiac, M., 2004. Direct identification of the damage behaviour of composite materials using the virtual fields method. Composites: Part A, 35, 841848.

Chu, T.C., Ranson, W.F., Sutton, M.A., Petters, W.H., 1985. Applications of digital image-correlation techniques to experimental mechanics. Experimental Mechanics 25(3), 232-244.

Cipollina, A., López-Inojosa, A., Flórez-López, J., 1995. A simplified damage mechanics approach to nonlinear analysis of frames. Computers and Structures 54(6), 1113-1126.

Claire, D., Hild, F., Roux, S., 2002. Identification of damage fields using kinematic measurements. Comptes Rendus de Mécanique 330, 729-734.

Claire, D., Hild, F., Roux, S., 2004. A finite element formulation to identify damage fields: The equilibrium gap method. International Journal for Numerical Methods in Engineering 61(2), 189-208.

Claire, D., Hild, F., Roux, S., 2007. Identification of a Damage Law by Using Full- Field Displacement Measurements. International Journal of Damage Mechanics 16(2), 179-197.

Çolak A., 2000. Density and strength characteristics of foamed gypsum. Cement \& Concrete Composites 22, 193-200.

Coquard P., 1992. Résistance mécanique des plâtres secs et humides. PhD thesis, Université Aix-Marseille, France.

Crouzeix, L., Périé, J.N., Collombet, F., Douchin, B., 2009. An orthotropic variant of the Equilibrium Gap Method applied to the analysis of a biaxial test on a composite material. Composites Part A 40(11), 1732-1740.

Curtin, W. A., 1991. Exact Theory of Fiber Fragmentation in SingleFilament Composite. Journal of Materials Science 26(19), 5239-5253.

Eberl, C., Gianola, D.S., Hemker, K. J., 2010. Mechanical Characterization of Coatings Using Microbeam Bending and Digital Image Correlation Techniques. Experimental Mechanics 50(1), 85-97. 
Evans, A. G., Domergue, J.-M., Vagaggini, E., 1994. Methodology for Relating the Tensile Constitutive Behavior of Ceramic-matrix Composites to Constituent Properties. Journal of the Americain Ceramic Society 77(6), 1425-1435.

Forquin, P., Rota, L., Charles, Y., Hild, F., 2004. A method to determine the toughness scatter of brittle materials. International Journal of Fracture 125(1), 171-187.

Gras, R., Leclerc, H., Roux, S., Otin, S., Schneider, J., Périé, J.N., 2013. Identification of the out-of-plane shear modulus of a 3D woven composite Experimental Mechanics 53, 719-730.

Grédiac, M., Hild, F. (editors), 2012. Full-field measurements and identification in solid mechanics. ISTE / Wiley, London (UK).

Gupta, N., Woldesenbet, E., 2005. Characterization of Flexural Properties of Syntactic Foam Core Sandwich Composites and Effect of Density Variation. Journal of Composite Materials 39(24), 2197-2212.

Hild, F., Domergue, J.M., Evans, A. G., Leckie, F. A., 1994. Tensile and Flexural Ultimate Strength of Fiber-Reinforced Ceramic-Matrix Composites. International Journal of Solids and Structures 31(7), 1035-1045.

Hild, F., Burr, A., Leckie, F. A., 1996. Matrix Cracking and Debonding in Ceramic-Matrix Composites. International Journal Solids and Structures 33(8), 1209-1220.

Hild, F., Feillard, P., 1997. Ultimate Strength Properties of Fiber-Reinforced Composites. Reliability Engineering and System Safety 56(3), 225-235.

Hild, F., Roux, S., 2006. Digital image correlation: from measurement to identification of elastic properties, a review. Strain 42, 69-80.

Hild, F., Roux, S., Gras, R., Guerrero, N., Marante, M.E., Flórez-López, J., 2009. Displacement measurement technique for Euler-Bernoulli kinematics. Optics and Lasers in Engineering 47, 495-503.

Hild, F., Roux, S., Guerrero, N., Marante, M. E., Flórez-López, J., 2011. Calibration of constitutive models of steel beams subject to local buckling by 
using digital image correlation. European Journal of Mechanics A/Solids $30,1-10$.

Hui, C. Y., Phoenix, S. L., Ibnabdeljalil, M., Smith, R. L., 1995. An Exact Closed Form Solution for Fragmentation of Weibull Fibers in a Single Filament Composite with Applications to Fiber-Reinforced Ceramics. Journal of the Mechanics and Physics of Solids 43(10), 1551-1585.

Leplay, P., Réthoré, J., Meille, M., Baietto, M. C., 2010. Damage law identification of a quasi-brittle ceramic from a bending test using digital image correlation. Journal of the European Ceramic Society 30(13), 2715-2725.

Leplay, P., Réthoré, J., Meille, M., Baietto, M. C., 2012. Identification of asymmetric constitutive laws at high temperature based on Digital Image Correlation. Journal of the European Ceramic Society 32(15), 3949-3958.

Leplay, P., Réthoré, J., Meille, S., Baietto, M. C., 2011. Identification of damage and cracking behaviours based on energy dissipation mode analysis in a quasi-brittle material using Digital Image Correlation. International Journal of Fracture 171(1), 35-50.

McGowan, P. A., 2007. Relationship between Moisture Content and Mechanical Properties of Gypsum Sheathing - Phase 2 Research. 11th Canadian Conference on Building Science and Technology, Banff, Alberta, 9 p.

Meille S., 2001. Etude de comportement mécanique du plâtre pris en relation avec sa microstructure. PhD thesis, INSA de Lyon, France.

Murat M., Pusztaszeri L., Gremion M., 1974. Corrélation texture cristallinepropriétés mécaniques de plâtres durcis, étude préliminaire. Matériaux et Construction 47(8), 337-385.

Périé, J.N., Leclerc, H., Roux, S., Hild, F., 2009. Digital Image Correlation and biaxial test on composite material for anisotropic damage law identification. International Journal Solids and Structures 46(11-12), 2388-2396.

Réthoré, J., Roux, S., Hild, F., 2007. From pictures to extended finite elements: extended digital image correlation (X-DIC). Comptes Rendus Mécanique 335, 131-137. 
Réthoré, J., Elguedj, T., Simon, P., Coret, M., 2009. On the use of NURBS functions for displacement derivatives measurement by digital image correlation. Experimental Mechanics 7(50), 1099-1116.

Roux, S., Hild, F., 2008. Digital Image Mechanical Identification (DIMI). Experimental Mechanics 48(4), 495-508.

Sakji M. S., 2006. Modélisation probabiliste et validation expérimentale du transfert thermique et du comportement thermomécanique avec endommagement d'une plaque multicouche carton-plâtre-carton soumise au feu. PhD thesis, université de Marne-La-Vallée, France.

Sakji, S., Soize, C., Heck, J., 2008. Probabilistic Uncertainty Modeling for Thermomechanical Analysis of Plasterboard Submitted to Fire Load. Journal of Structural Engineering 134(10), 1611-1618.

Sutton, M.A., Wolters, W. J., Peters, W. H., Ranson, W. F., McMeill, S. R., 1983. Determination of displacements using an improved digital correlation method. Image and Vision Computing 1(3), 133-139.

Vimmrová A., Keppert M., Svoboda L., Černý R., 2011. Lightweight gypsum composites: Design strategies for multi-functionality. Cement \& Concrete Composites 33, 84-89. 


\section{List of Figures}

1 Simply supported plate in its reference (a) and deformed (b) states for the last load level before failure. The black speckle paint applied onto the surface is used for DIC analyses. The analyzed ROI (white box) and the neutral axis (dashed line) are shown for the reference configuration . . . . . . . . . . 19

2 Typical experimental load-deflection curve of the four-point bending test. Point A shows the elastic response, point B the inception of cracks in the plaster core, and C final failure . . . 19

3 Load-deflection curves from four-point bending test on plasterboard. Note that in spite of the coarse microstructure of plaster and its brittle behavior, the overall variability of the load-deflection response is modest . . . . . . . . . . . 20

4 Longitudinal displacement fields $u_{D I C}$ expressed in pixels (1 pixel $\leftrightarrow 37 \mu \mathrm{m})$ and longitudinal strain fields $\epsilon_{x x}$ in $\%$ during an experiment as obtained from DIC, (a) elastic regime, (b) inception of damage, (c) before failure . . . . . . . . . . 21

5 The 4-point bending setup, dimensions in mm. . . . . . . . . 22

6 Identified positions of the applied load point and their theoretical positions (dotted lines) for ten tests . . . . . . . . . . 22

7 Deflection curve before failure. The ${ }^{*}$ symbols show the deflection measured by DIC. The solid line is the result of the identified damage law. A very good agreement is observed over the entire field of view . . . . . . . . . . . . . . . . 23

8 Damage parameter versus curvature for one sample for all load levels. Note that each load level is analyzed independently, and yet the scatter in the twenty seven different determinations of this damage growth law is small . . . . . . . . . 23

9 Change of the identified loads $q_{2}$ and $q_{3}$ all along the test in the damage regime. In an ideal test, the ratio $q_{2} /\left(q_{2}+q_{3}\right)$ is constant and equal to $0.5 \ldots \ldots \ldots$. . . . . . . . . 24 


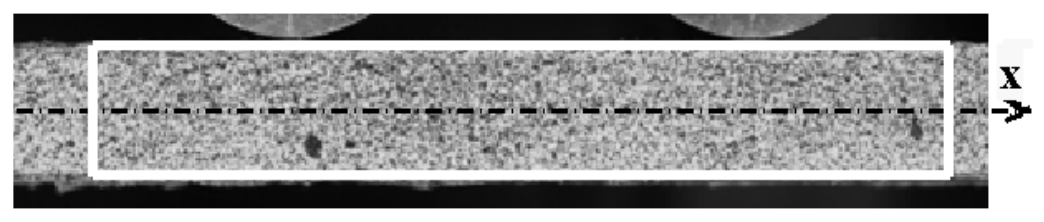

(a)

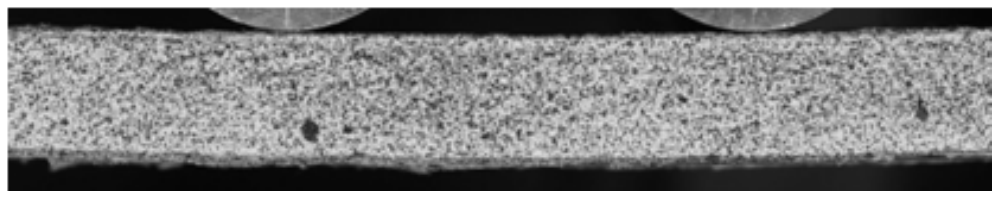

(b)

Figure 1: Simply supported plate in its reference (a) and deformed (b) states for the last load level before failure. The black speckle paint applied onto the surface is used for DIC analyses. The analyzed ROI (white box) and the neutral axis (dashed line) are shown for the reference configuration

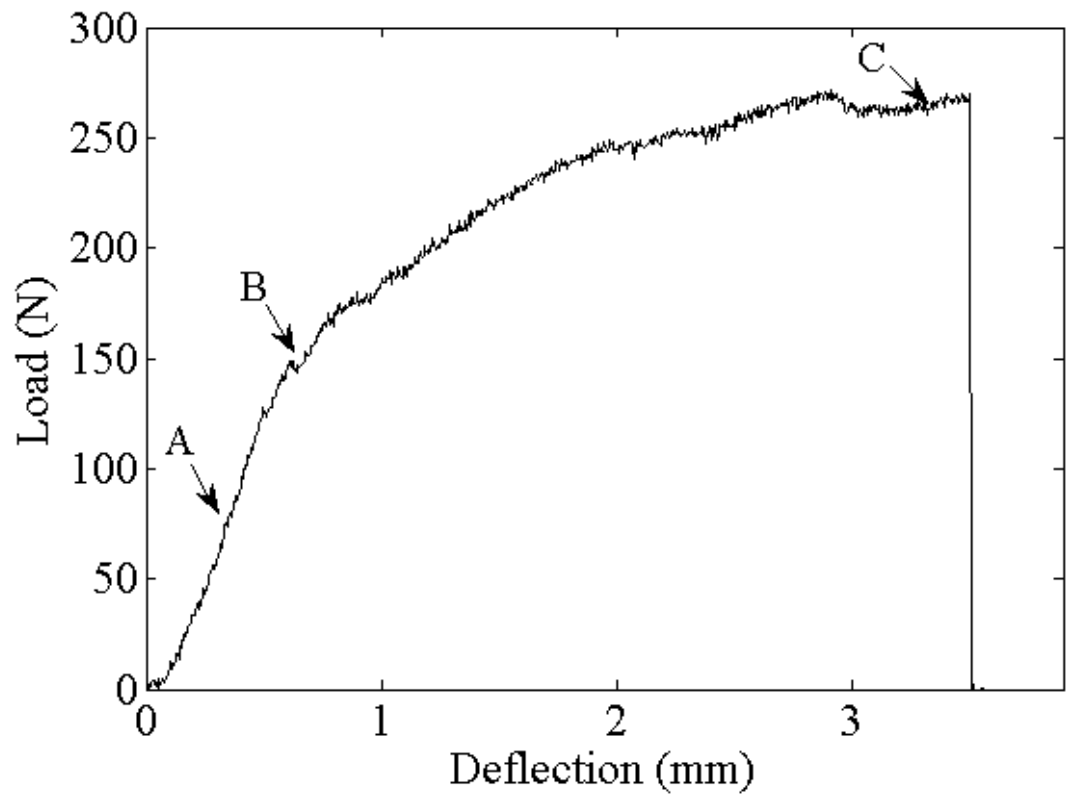

Figure 2: Typical experimental load-deflection curve of the four-point bending test. Point A shows the elastic response, point $\mathrm{B}$ the inception of cracks in the plaster core, and $\mathrm{C}$ final failure 


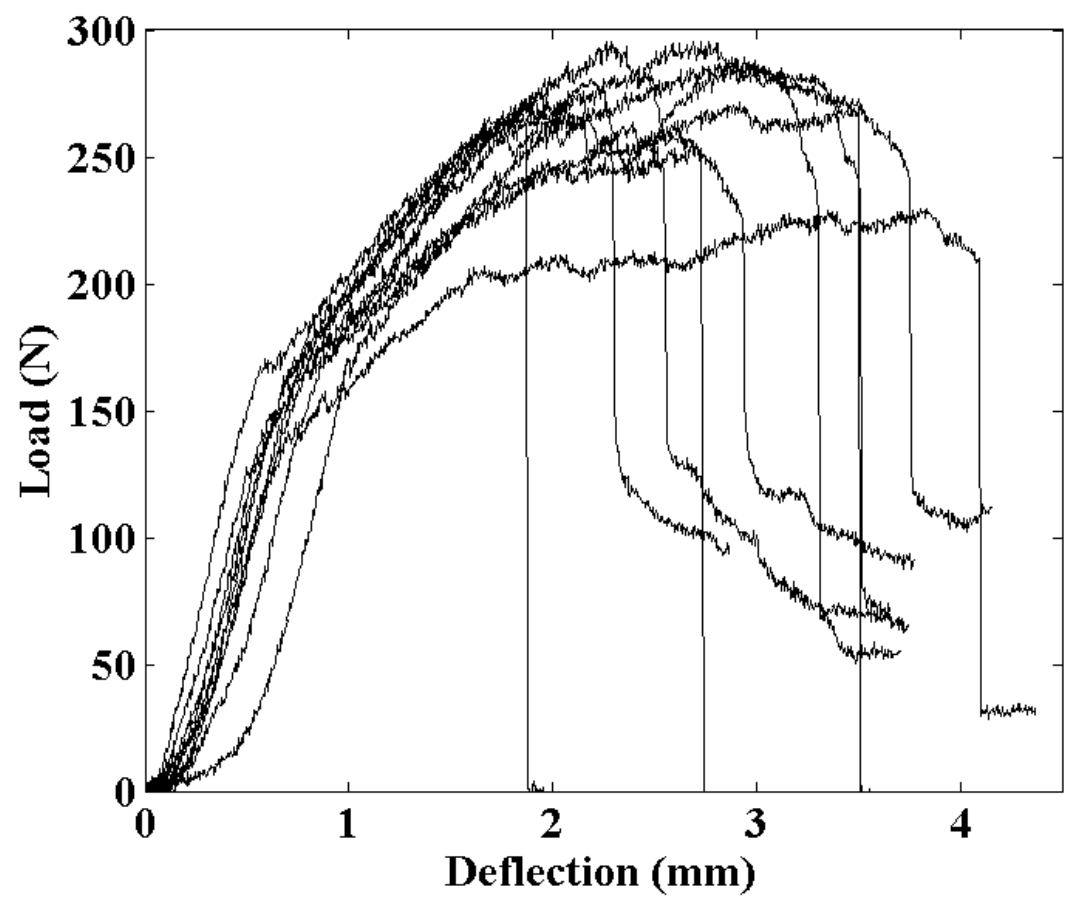

Figure 3: Load-deflection curves from four-point bending test on plasterboard. Note that in spite of the coarse microstructure of plaster and its brittle behavior, the overall variability of the load-deflection response is modest 

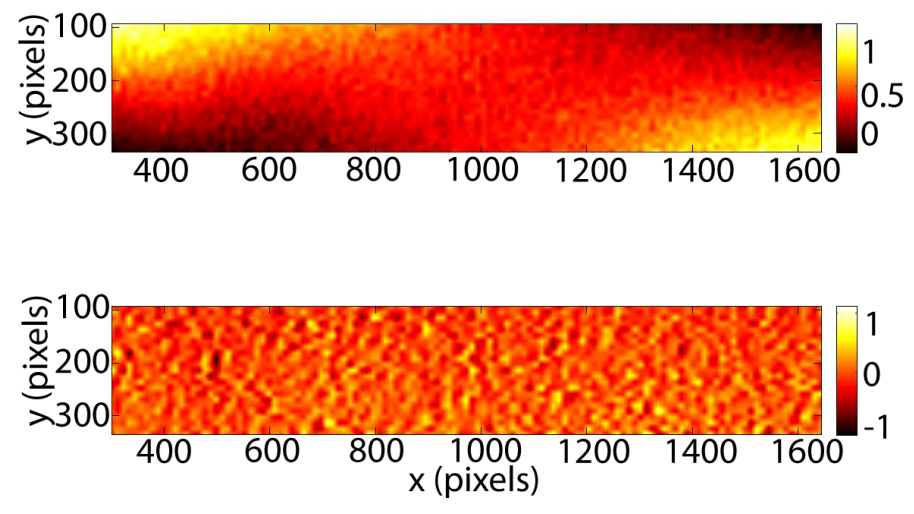

(a)
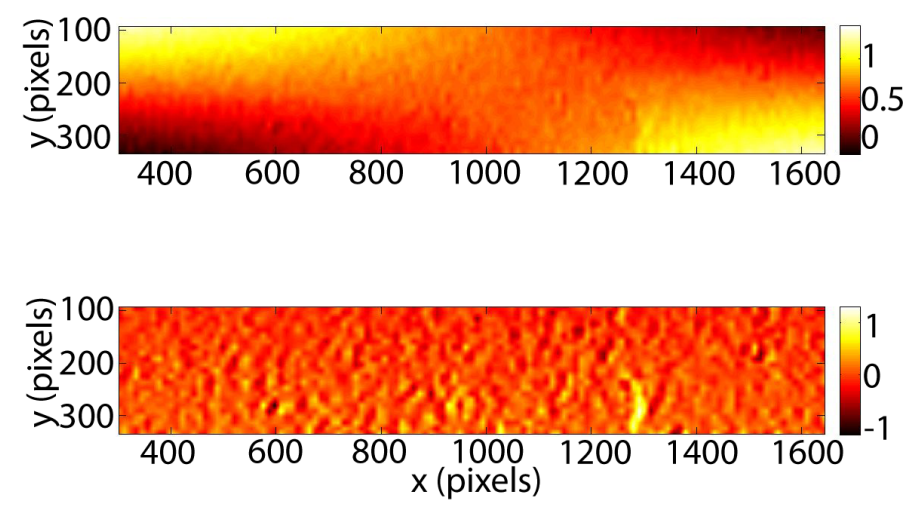

(b)
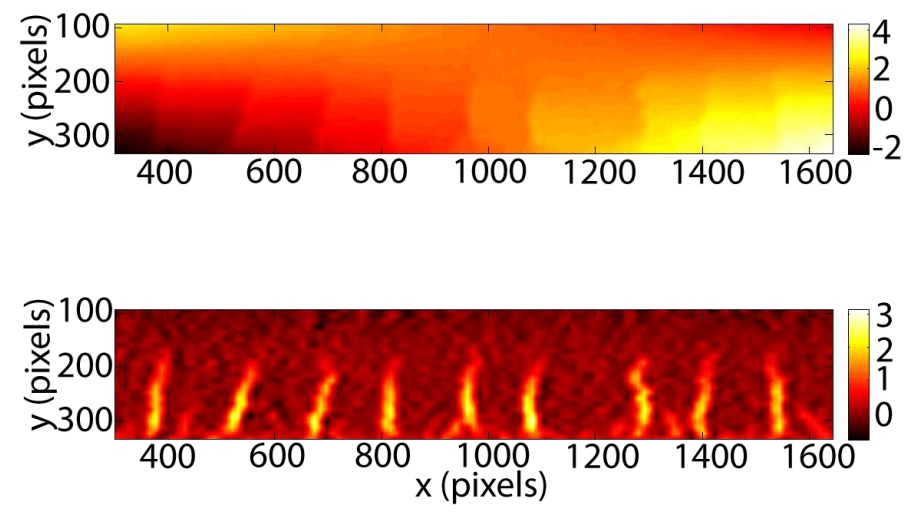

(c)

Figure 4: Longitudinal displacement fields $u_{D I C}$ expressed in pixels (1 pixel $\leftrightarrow 37 \mu \mathrm{m}$ ) and longitudinal strain fields $\epsilon_{x x}$ in $\%$ during an experiment as obtained from DIC, (a) elastic regime, (b) inception of damage, (c) before failure 


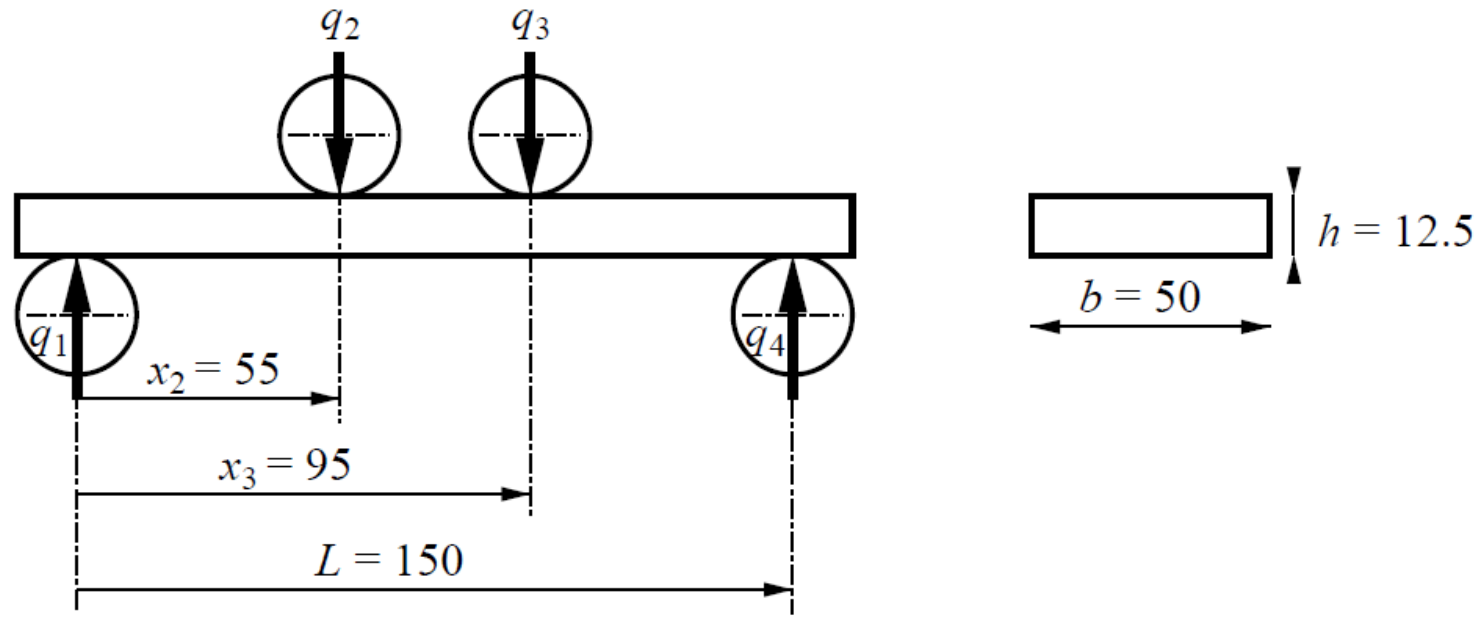

Figure 5: The 4-point bending setup, dimensions in $\mathrm{mm}$.

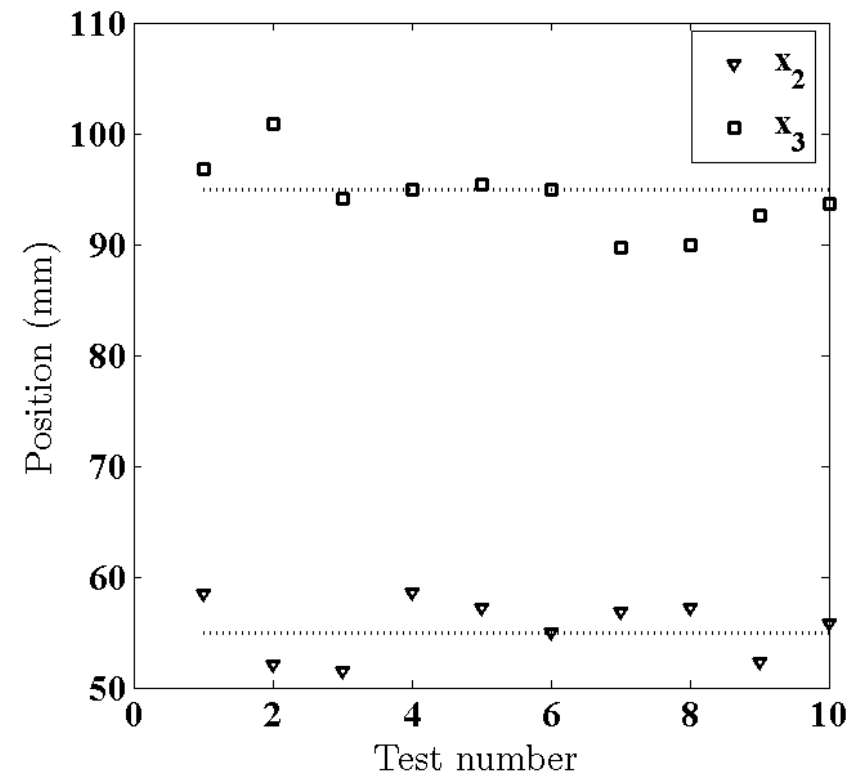

Figure 6: Identified positions of the applied load point and their theoretical positions (dotted lines) for ten tests 


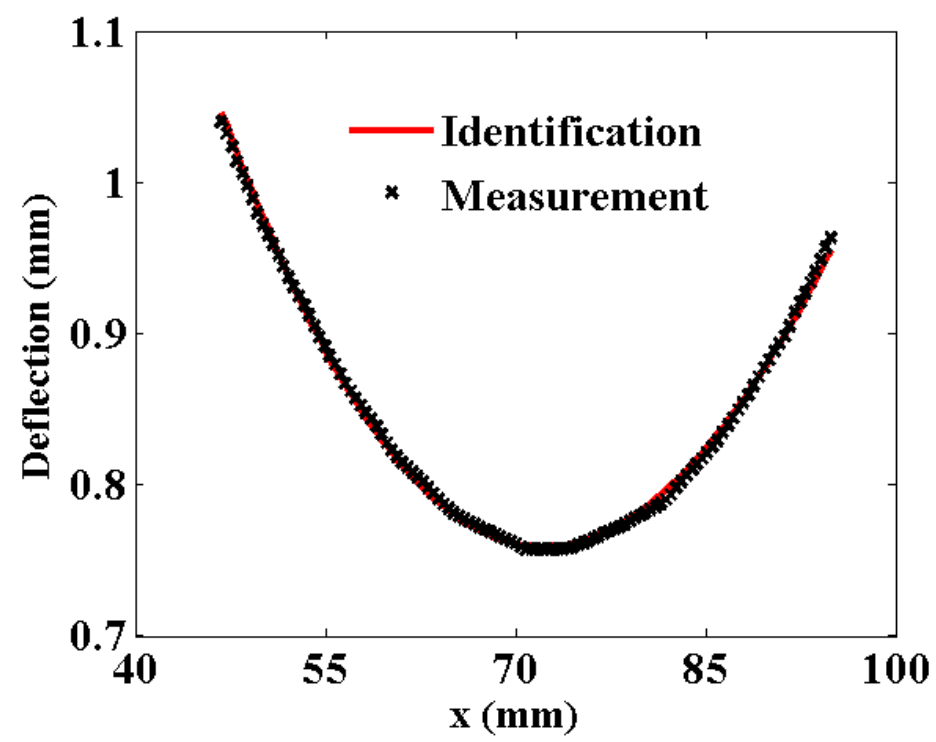

Figure 7: Deflection curve before failure. The ${ }^{*}$ symbols show the deflection measured by DIC. The solid line is the result of the identified damage law. A very good agreement is observed over the entire field of view

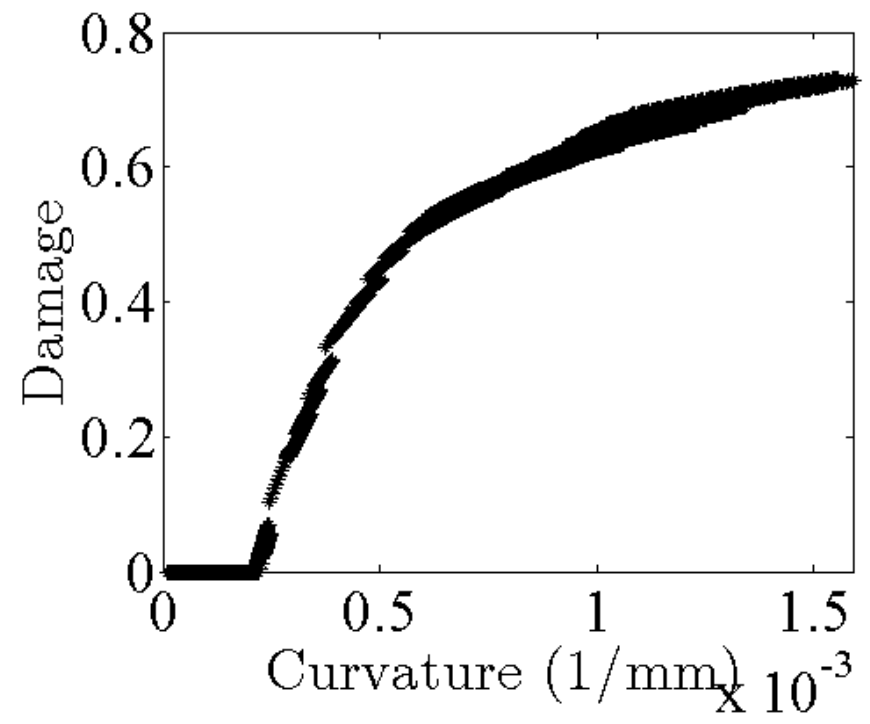

Figure 8: Damage parameter versus curvature for one sample for all load levels. Note that each load level is analyzed independently, and yet the scatter in the twenty seven different determinations of this damage growth law is small 


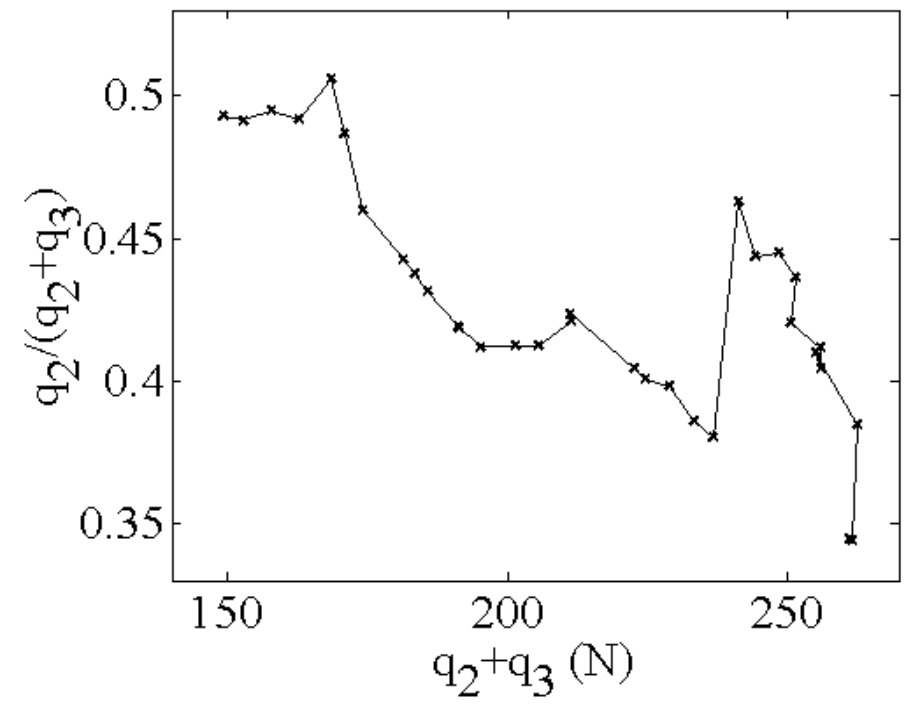

Figure 9: Change of the identified loads $q_{2}$ and $q_{3}$ all along the test in the damage regime. In an ideal test, the ratio $q_{2} /\left(q_{2}+q_{3}\right)$ is constant and equal to 0.5 